\title{
ANALISIS PEMASANGAN SISTEM AC PADA MOBIL MINIBUS
}

\author{
Engkos Koswara \\ Fakultas Teknik, Universitas Majalengka \\ email: ekoswara.ek@gmail.com
}

\begin{abstract}
Transportation is a need of many people. Especially for people with high mobility demands needs. Not only as a supporter of the worker's mobility, transportation should also be a second home for the owner. Thus the transportation should be made as comfortable as possible. Minibus vehicle cabin will be very hot when the condition of the silencer in the cabin has been down in performance. Especially the silencers which are used to muffle the heat from the machine. Temperature of heat will be greater felt in Minibus cars that have the position of the engine under the car than the minibus car that has the position of the machine in front. Although Minibus cars are equipped with AC (Air Conditioner), cold air produced AC is not so felt due to damage to the heat sink used. This is the focus of attention of researchers to examine further why such things can happen by using software tools CFD.The heat damper on the minibus car cabin is helpful in retaining the heat coming into the cabin, be it from the environment or from the engine heat of the vehicle itself. In simulation using 1 blower AC can conditioned cabin space with temperature $18-25^{\circ} \mathrm{C}$. And The number of AC blower points on the minibus car is helpful in cooling the cabin space.
\end{abstract}

Keywords: Minibus vehicle, AC (Air Conditioner), CFD Software

\section{PENDAHULUAN}

Moda trasnportasi yang paling banyak digemari adalah mobil terutama mobil minibus karena mobil tersebut dapat menampung banyak anggota keluarga. Sehingga sampai saat ini banyak pabrikan otomotif berlomba - lomba dalam membuat minibus.

Kabin kendaraan minibus akan sangat terasa panas apabila kondisi peredam pada kabin sudah turun kinerjanya. Terutama peredam yang yang digunakan untuk meredam panas dari mesin. Temperature panas akan lebih besar dirasakan pada mobil minibus yang mempunyai posisi mesin di bawah mobil dibandingkan dengan mobil minibus yang mempunyai posisi mesin didepan.

Meskipun mobil minibus sudah dilengkapi dengan AC (Air Conditioner), udara dingin yang dihasilkan AC tersebut tidak begitu terasa akibat rusaknya peredam panas yang digunakan. Hal tersebut menjadi focus perhatian peneliti untuk mengkaji lebih jauh kenapa hal demikian dapat terjadi dengan menggunakan alat bantu software.

Koswara, E., 2017, mengatakan penggunaan 1 titik sumber pemanas menyebabkan sebaran panas tidak merata. Sama halnya dengan penggunaan AC yang menggunakan 1 titik dan lebih dari satu titik. Dalam penelitian ini akan dilakukan penelitian untuk mengkaji sebaran dingin dengan menggunakan 1 titik AC dan 2 titik AC.

Tujuan dari penelitian ini adalah untuk melihat sebaran udara AC pada ruang kabin minibus dan seberapa efisien penggunaan peredam panas pada kabin.

\section{METODE PENELITIAN}

Adapun tahapan - tahapan penelitian adalah sebagai berikut :

1. Studi literature

Pada tahapan ini dilakukan pencairan data berupa jurnal - jurnal terkait dengan penelitian 
yang akan dilaksanakan

2. Survey lapangan

Pada tahapan ini, akan dilakukan pengamatan langsung di lapangan. Yaitu melihat secara langsung kondisi kabin mobil minibus

3. Pengambilan data

Pada saat alat pengering digunakan/diuji coba, dilakukan pengambilan data yang dibutuhkan dalam penelitian. Misalkan, temperature, tekanan operasi, dan lain sebagainya.

4. Pengolahan data/simulasi CFD

Setelah pengambilan data pada tahap sebelumnya, kemudian data yang telah diperoleh dilakukan pengolahan data/simulasi CFD pada software untuk melihat sebaran panas yang terjadi.

5. Analisis data

Setelah melihat sebaran dingin yang terjadi, kemudian dilakukan analisis data.

6. Kesimpulan dan saran

Penarikan kesimpulan dilakukan setelah analisis data pada tahap sebelumnya dilakukan.

\section{HASIL DAN PEMBAHASAN}

\section{Pengambilan Data}

Pengambilan data dilakukan untuk menunjang proses penelitian. Data - data yang dibutuhkan yaitu dimensi ruang kabin mobil minibus, temperatur udara yang keluar dari kisi AC mobil, kecepatan angin yang dihembuskan oleh AC mobil.

a. Dimensi ruang kabin

Pengambilan data dimensi dilakukan untuk pembuatan model pada software yang akan dibuat. Meliputi ukuran panjang, lebar, tinggi, ketebalan material hingga jenis - jenis material yang digunakan pada mobil minibus.

b. Temperatur Udara (AC)

Temperatur udara (AC) diambil sebagai data kajian dalam melakukan simulasi pada software, dalam hal ini software yang digunakan adalah Autodesk CDF Simulation. Pengukuran temperatur menggunakan Termometer Infrared.

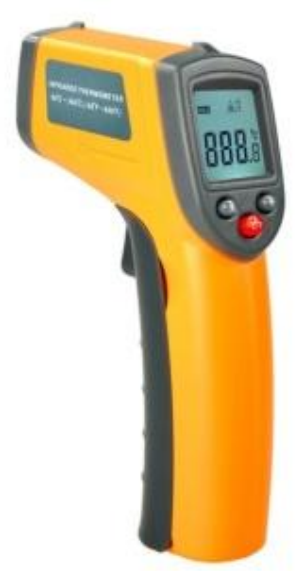

Gambar 1: Termometer Infrared

c. Kecepatan Udara (AC)

Kecepatan udara (AC) diambil sebagai data kajian dalam melakukan simulasi pada software. Pengukuran kecepatan udara menggunakan Anemometer.

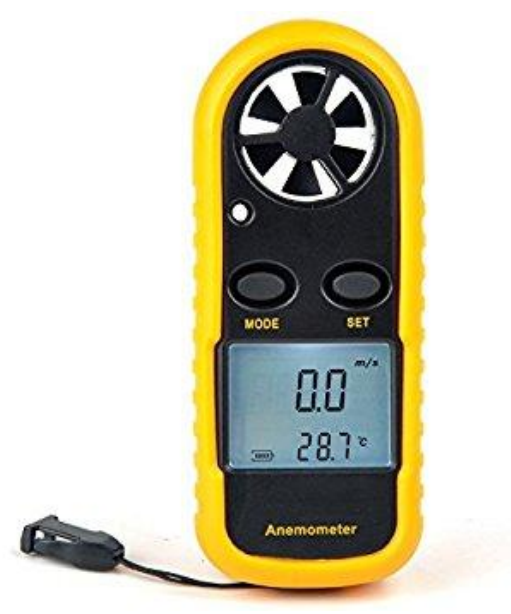

Gambar 2: Anemometer

\section{Pengolahan Data}

Pengolahan data dilakukan menggunakan 2 software, yaitu :

a. Solidwork; software ini digunakan sebagai alat untuk membuat model dari sistem nyata yang ada, dalam hal ini adalah mobil minibus.

b. Autodesk CFD simulation; software ini digunakan sebagai alat untuk mensimulasikan sistem nyata dalam pemodelan, dalam hal ini yang menjadi fokus adalah simulasi dinamika fluida yang terjadi dalam sebuah sistem. 
ulang hingga domain terpenuhi.

Terdapat beberapa tahapan dalam penelitian, diantaranya:

a. Pembuatan model

Pembuatan model dilakukan pada software

Solidwork dengan dimensi yang telah ditentukan pada tahapan pengambilan data.

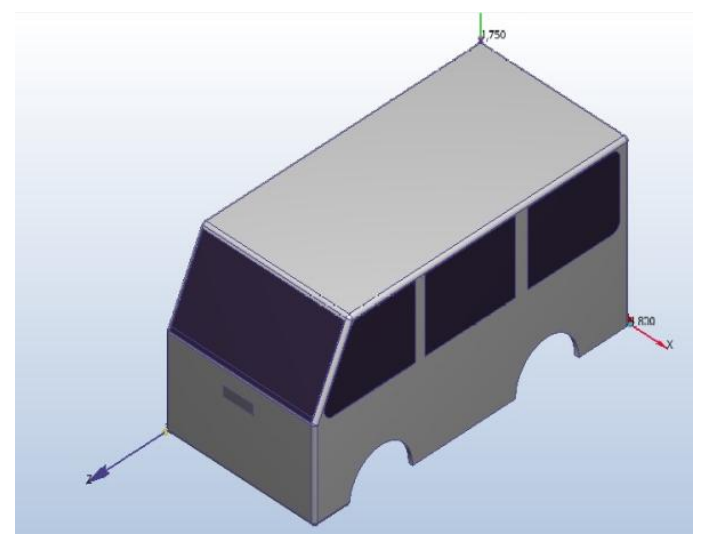

Gambar 3: Model Minibus

b. Penentuan parameter simulasi

Terdapat beberapa parameter dalam simulasi software, diantaranya :

1) Material yang digunakan

- Plat baja

- Peredam Panas

- kaca

2) Temperatur udara (AC) sebesar $18^{\circ} \mathrm{C}$

3) Kecepatan udara (AC) sebesar $2 \mathrm{~m} / \mathrm{s}$

4) Beban pendingin

- Panas dari lingkungan sebesar $35^{\circ} \mathrm{C}$

- Panas dari mesin sebesar $120^{\circ} \mathrm{C}$

c. Meshing model

Pada tahapan ini, dilakukan pendekatan dalam melakukan analisis menggunakan software. Meshing merupakan tahapan proses dimana geometri secara keseluruhan dibagibagi dalam elemen-elemen kecil. Elemenelemen kecil ini nantinya berperan sebagai kontrol surface atau volume dalam proses perhitungan yang kemudian tiap-tiap elemen ini akan menjadi inputan untuk elemen disebelahnya. Hal ini akan terjadi berulang-

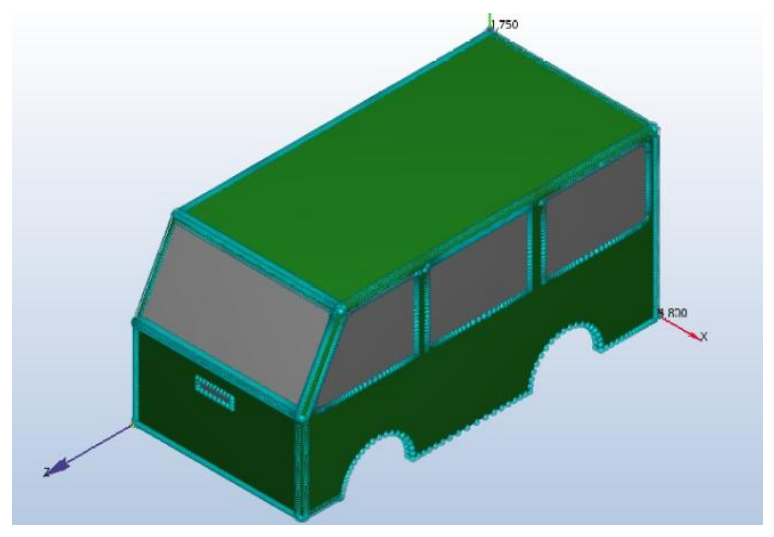

Gambar 4: Meshing model

d. Hasil simulasi software

Simulasi software dilakukan dengan beberapa tahapan, diantaranya :

1) Tanpa menggunakan Peredam Panas Simulasi dilakukan tanpa menggunakan pelapis berupa peredam panas. Simulasi dilakukan dengan menggunakan 1 dan 2 blower. Gambar 3.5 Menunjukan sebaran Udara AC di dalam kabin dengan menggunakan 1 blower tanpa peredam.
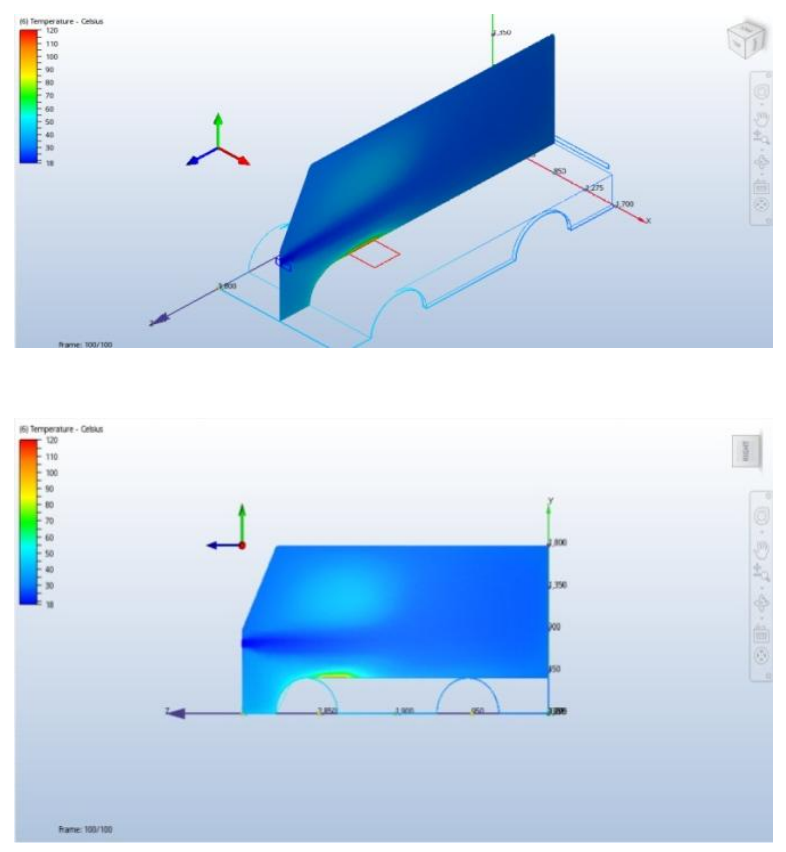

Gambar 5: Sebaran udara AC menggunakan 1 blower tanpa peredam 
Tahapan berikutnya mensimulasikan sebaran udara AC dengan menggukanan 2 blower tanpa peredam. Gambar 3.6 Menunjukan sebaran AC dengan 2 blower tanpa peredam.
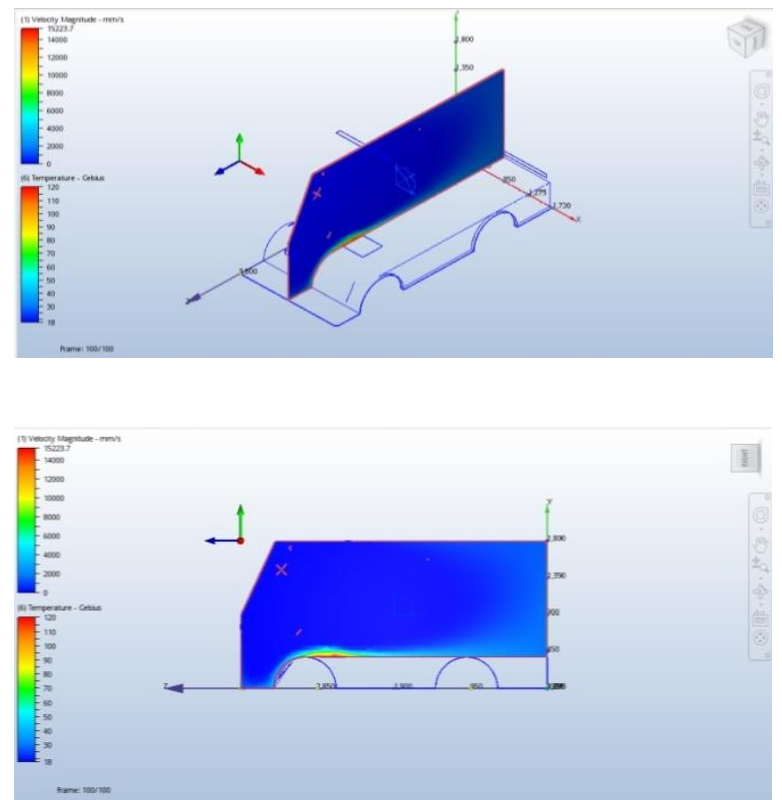

Gambar 6: Sebaran udara AC menggunakan 2 blower tanpa peredam

2) Menggunakan Peredam panas

Simulasi dilakukan dengan menggunakan peredam panas. Simulasi dilakukan menggunakan 1 dan 2 blower. Gambar 3.7 Menunjukan sebaran AC dengan menggunakan 1 dan 2 blower dengan menggunakan peredam.
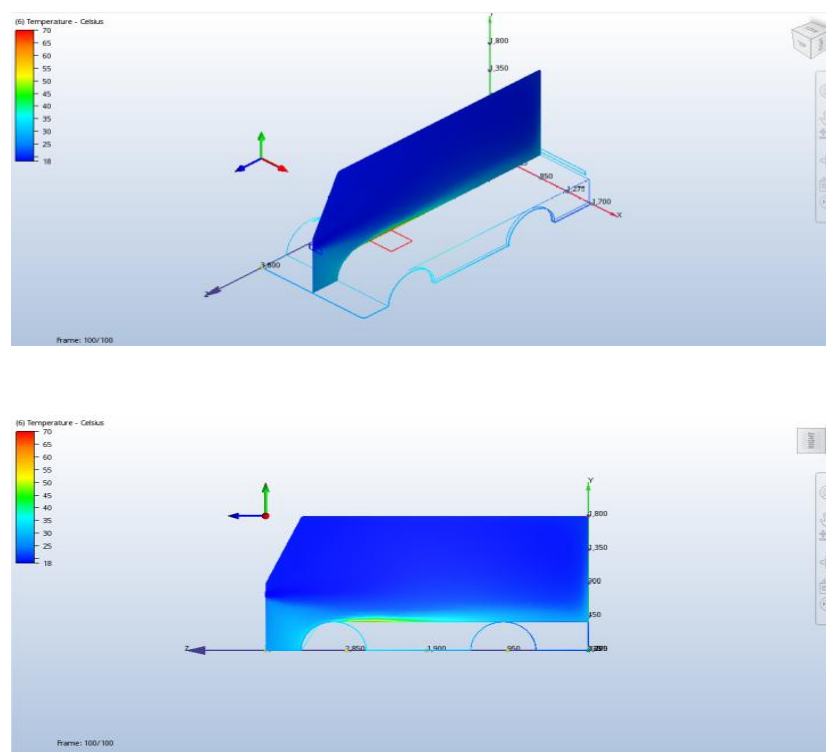

Gambar 7: Sebaran udara AC menggunakan 1 blower dengan peredam
Selanjutnya dilakukan simulasi dengan menggunakan 2 blower dengan peredam. Gambar 3.8 Menunjukan sebaran udara AC 2 blower dengan peredam.
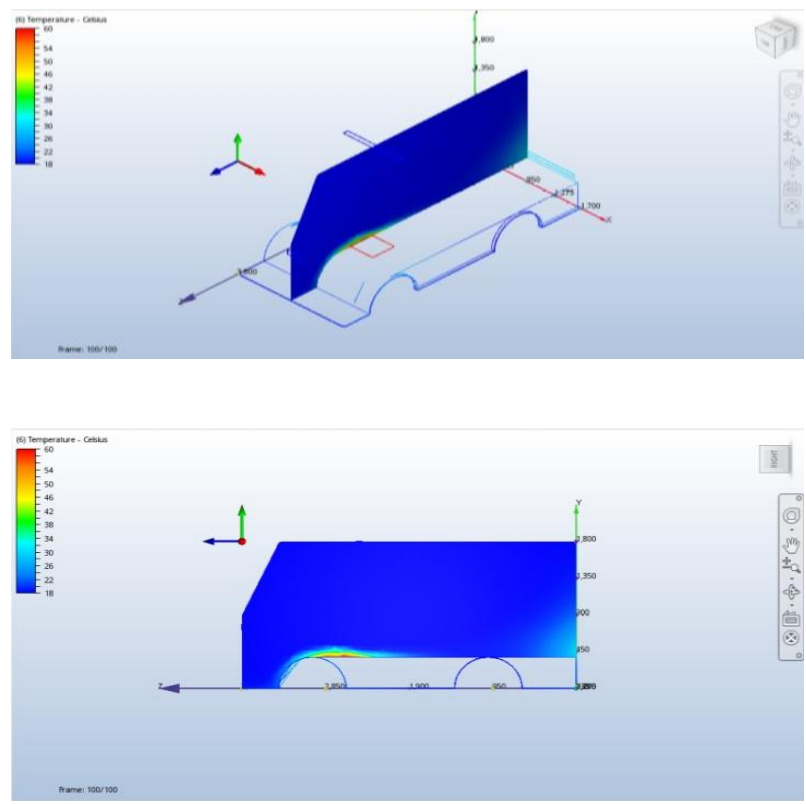

Gambar 8: Sebaran udara Ac menggunakan 2 blower menggunakan peredam

\section{Analisis Data}

Dari hasil simulasi yang telah dilakukan, terdapat beberapa pengamatan. Diantaranya :

1. Tanpa menggunakan peredam panas

Ketika tidak menggunakan peredam panas, udara dingin dari AC tidak menyebar dengan baik. Hal tersebut diakibatkan besarnya panas yang masuk ke dalam kabin minibus.

Dengan menggunakan 2 blower lebih teratasi panas yang masuk ke dalam kabin dibandingkan dengan 1 blower. Dapat dilihat pada gambar 4.6 Udara AC di dalam kabin dominan $30-40^{\circ} \mathrm{C}$.

2. Menggunakan peredam panas

Dengan menggunakan peredam panas pada kabin minibus, panas dari luar baik dari mesin ataupun lingkungan luar cukup terhambat untuk masuk ke dalam kabin minibus, akibatnya udara dingin dari AC dapat menyebar dengan baik.

Dengan menggunakan 1 blower panas yang masuk ke dalam kabin lebih rendah 
dibandingkan dengan tanpa menggukana peredam. Gambar 3.7 Menunjukan dominasi temperatur masih di angka 18$25^{\circ} \mathrm{C}$, akan lebih baik lagi apabila menggunakan 2 blower yang ditunjukan pada gambar 3.8 Menunjukan dominasi temperatur masih diangka $18-22^{\circ} \mathrm{C}$.

\section{KESIMPULAN}

Berdasarkan penelitian yang telah dilakukan, terdapat beberapa hal yang dapat disimpulkan. Diantaranya :

1. Peredam panas pada kabin mobil minibus sangat membantu dalam menahan panas yang masuk ke dalam kabin, baik itu dari lingkungan maupun dari panas mesin kendaraan itu sendiri. Dalam simulasi menggunakan 1 blower AC dapat terkondisikan ruang kabin dengan temperatur $18-25^{\circ} \mathrm{C}$.

2. Pengaruh peredam terhadap serapan panas baik yang keluar dari mesin ataupun dari lingkungan sangat berpengaruh besar. 1 blower AC dengan menggunakan peredam mampu menjaga ruang kabin berada pada temperatur $18-25^{\circ} \mathrm{C}$, sedangkan dengan 2 blower AC dapat menjang ruang kabin pada temperatur $18-22^{\circ} \mathrm{C}$.

3. Jumlah titik blower AC pada mobil minibus sangat membantu dalam pendinginan ruang kabin.normal.

\section{REFERENSI}

J. P. HOLMAN, Perpindahan Kalor, Edisi Keenam

- Koswara, E., 2017. Analisis Penyebaran Panas Pada Alat Pengering Jagung Menggunakan CFD (Studi Kasus UPTD Balai Benih Palawija Cirebon). JENSITEC, 3(2). 